\title{
AVALIAÇÃO DOS PROCEDIMENTOS HIGIÊNICO-SANITÁRIOS EM 6 AÇOUGUES NO MUNICÍPIO DE CONFRESA-MT
}

\author{
Evaluation of the hygienic and sanitary procedures in the butcheries of Confresa-MT
}

\author{
Juesla Silva Torres $^{1}$ (D), Leandro Ales Lacerda ${ }^{2}$ (D)
}

Recebido em 15 de abril de 2021 | Aprovado em 30 de junho de 2021

\begin{abstract}
RESUMO
Importante instrumento para assegurar a qualidade e a segurança dos alimentos, as Boas Práticas de Fabricação, são requisitos da legislação vigente, as quais devem ser aplicadas desde a recepção de matéria-prima, processamento, até a distribuição dos produtos. O objetivo deste trabalho foi avaliar à higiene pessoal e a utilização de Equipamentos de Proteção Individual (EPI's) pelos colaboradores durante a manipulação dos produtos, além da infraestrutura interna dos açougues. Foram avaliados 6 açougues aleatórios, por meio de aplicação de check-list, realizando-se o preenchimento dos itens em C (quando o item observado estava conforme), NC (quando o item estava inadequado ou irregular) e NA (quando o item não se aplicava ao estabelecimento). Os açougues A, B e E, compõe o GRUPO 3, representado pela faixa de 0 a $50 \%$ de atendimento dos itens, e portanto, classificando, como açougues deficientes ou que não tem controle sobre os procedimentos de Boas Práticas de Fabricação. Os açougues C, D e F, enquadram-se no GRUPO 2, representado pela faixa de 51 a $75 \%$ de atendimento dos itens, classificando-se em bons.
\end{abstract}

Palavras-chave: Boas Práticas;Higiene; Manipulação

\begin{abstract}
Important tool to ensure food quality and safety, Good Manufacturing Practices are requirements of current legislation, which must be applied from there ception of raw material, processing, to the distribution of products. The objective of this work was to evaluate personal hygiene and the use of Personal Protective Equipment (PPE) by employe esduring product handling, in addition to the internal in frastructure of the butcher and compare them with the handling practices established in the Good Manufacturing Practices Program for food. Six random butcheries were evaluated, through the application of a check-list, filling in the items in $\mathrm{C}$ (when the observed item wascompliant), NC (whenthe item was inadequate or irregular) and NA (when the item did not applytothe establishment). Butcheries A, B and E, make up GROUP 3, represented by the range from 0 to $50 \%$ of attendane of the items, and there for, classifying as butcheries with disabilities or Who have no control over the procedures of Good Manufacturing Practices. Butcheries C, D and F, fallin to GROUP 2, represented by the range from 51 to $75 \%$ of attendance of theitems.
\end{abstract}

Keywords: Good Practices; Hygiene; Manipulation.

\footnotetext{
${ }^{1}$ Graduanda em Bacharelado em Agronomia, no Instituto Federal de Educação, Ciência e Tecnologia do Mato Grosso (IFMT), Campus Confresa. E-mail: juhtorres92@gmail.com

${ }^{2}$ Mestre em Ciência e Tecnologia de Alimentos. Professor no Instituto Federal de Educação, Ciência e Tecnologia do Mato Grosso(IFMT),Campus Confresa E-mail:leandro.lacerda@ifmt.edu.br
} 


\section{Introdução}

A carne é um dos alimentos mais consumidos no mundo. Tem-se notado atualmente uma mudança de comportamento tanto nas áreas produtivas, quanto nas áreas de consumo. Ultimamente intensificaram-se os estudos acerca das doenças de origem alimentar, visto que, as ocorrências clínicas decorrentes da ingestão de alimentos por contaminações microbiológicas têm provocado constantes mudanças nos procedimentos de controle higiênicosanitário na produção dos alimentos (SILVA JUNIOR, 2010).

Importante instrumento para assegurar a qualidade e a segurança dos alimentos, as Boas Práticas de Fabricação, são requisitos da legislação vigente, as quais devem ser aplicadas desde a recepção de matéria-prima, processamento, até a distribuição dos produtos (BRASIL, 2004).

A cerca das instalações, estas devem possuir lavatórios exclusivos para a higiene das mãos na área de manipulação, com sabonete líquido, inodoro, anticéptico e toalhas de papel não reciclado. Os sanitários e vestiários não devem se comunicar com a área de preparação e armazenagem. Estes devem possuir lavatórios e estar supridos de produtos destinados a higiene pessoal (BRASIL, 2004).

Quanto aos colaboradores, estes devem ser capacitados periodicamente em higiene pessoal, manipulação higiênica e doenças transmitidas por alimentos. Devem portar uniformes condizentes a atividade, limpos e conservados (TANCREDI, et al., 2006).

Dado a importância da adoção de Boas Práticas de Fabricação nos estabelecimentos alimentícios para a garantia e segurança dos alimentos, objetivou-se neste trabalho avaliar à higiene pessoal e a utilização de Equipamentos de Proteção Individual (EPI’s) pelos colaboradores durante a manipulação dos produtos, avaliar a infraestrutura interna do açougue e compará-las as práticas de manipulação com as normas estabelecidas no Programa de Boas Práticas de Fabricação dos alimentos estabelecidos pela ANVISA.

\section{Material e Métodos}

O estudo observacional, descritivo, quantitativo e qualitativo foi conduzido no município de Confresa-MT, situada ao Nordeste do Estado de Mato Grosso, no mês de janeiro de 2021. A pesquisa foi realizada in loco com a verificação de checklist, conforme orientação da RESOLUÇÃO- RDC Nº 275, de 21 de outubro de 2002, da ANVISA, onde foram analisados os seguintes apêndices: 1) Infraestrutura e higienização das instalações, equipamentos, controle integrado de pragas, abastecimento de água; 2) Equipamentos, móveis e utensílios; 3) Saúde e hábitos higiênicos dos manipuladores; 4) Produção e transporte do alimento. 
Atualmente encontra-se em funcionamento aproximadamente 20 açougues, sendo a maioria localizados em supermercados, dos quais foram selecionados aleatoriamente $6(30 \%)$ açougues. Os estabelecimentos foram selecionados de acordo com a cooperação dos proprietários.

Para cada estabelecimento foi utilizado um checklist contendo 94 itens, onde através de observação direta e sem interferência foram avaliados cada um dos itens. Realizando-se o preenchimento dos itens em $\mathrm{C}$ (quando o item observado estava conforme), $\mathrm{NC}$ (quando o item estava inadequado ou irregular) e NA (quando o item não se aplicava ao estabelecimento). Do total avaliado, foram contabilizados os itens não conformes, conformes e não aplicáveis.

Os dados obtidos foram analisados por meio da tabulação dos itens em planilha do programa Microsoft Office ${ }^{\circledR}$ 2013, onde foram calculados os percentuais de conformidades e não conformidades para classificação do estabelecimento que é dividida em três grupos e, classificam-se em deficientes, regular e bom conforme percentual de atendimento dos itens: (1) 76 a $100 \%$ de atendimento dos itens, (2) 51 a $75 \%$ de atendimento dos itens e (3) 0 a $50 \%$ de atendimento dos itens.

\section{Resultados e Discussão}

Dos dados obtidos foram calculados os percentuais de conformidades como observado no Gráfico 1, para a classificação dos açougues em grupos.

Gráfico 1- Percentual de Conformidades de atendimento aos itens verificados na aplicação do check-list

\section{Percentual de Conformidades na avaliação do check-list}

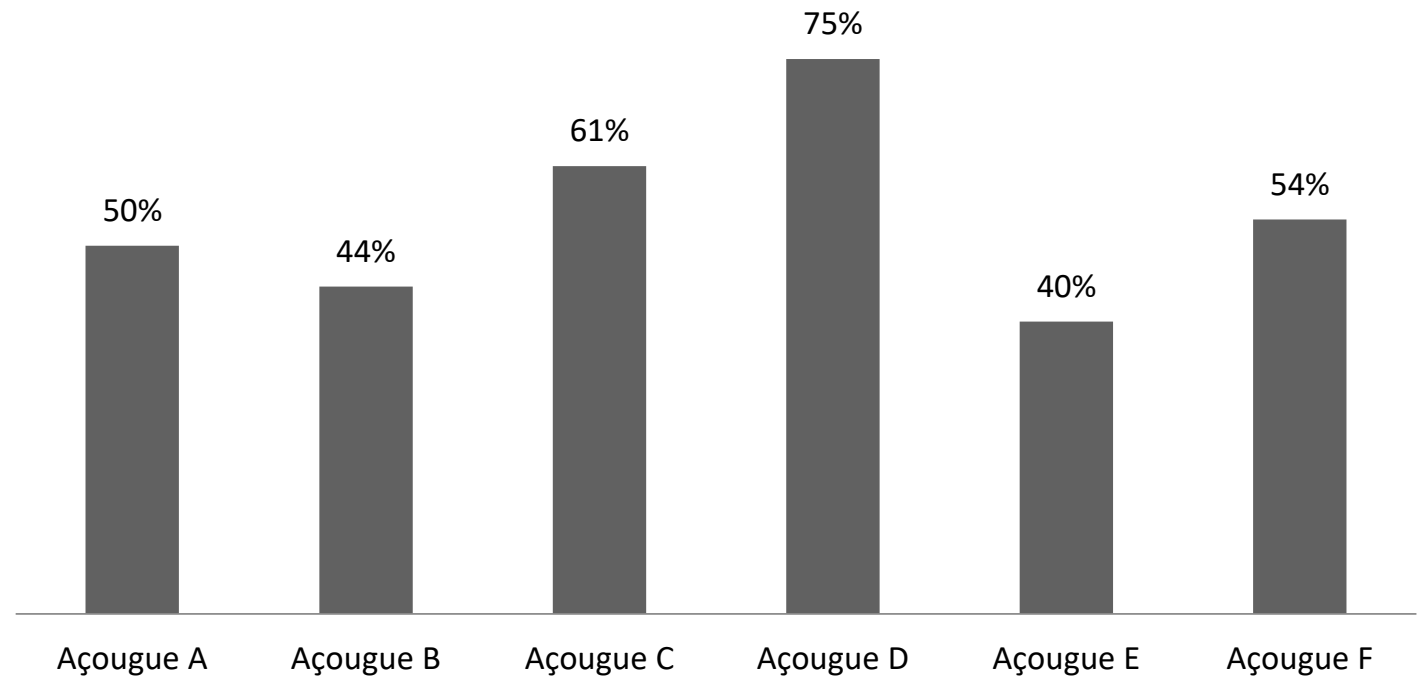

Fonte: Autores. 
Dessa forma, os açougues A, B e E, compõe o GRUPO 3, representado pela faixa de 0 a 50\% de atendimento dos itens, e, portanto, classificando, como açougues deficientes ou que não tem controle sobre os procedimentos de Boas Práticas de Fabricação.

Já os açougues C, D e F, enquadram-se no GRUPO 2, representado pela faixa de 51 a 75\% de atendimento dos itens, caracterizando-se como estabelecimentos regulares, possuindo controle razoável sobre seus processos higiênicos e sanitários.

Não houve nenhum açougue com atendimento superior a 75\% de atendimento dos itens o qual seria classificado em ótimo ou altamente detentor dos processos de higiene.

Dentre as não conformidades observadas a predominância foi relacionada a instalações e edificações evidenciados pelas imagens contidas na Figura 1, como objetos em desuso na área de produção, piso quebrados ou com rachadura, ausência de coletores de lixo sem acionamento manual, instalações elétricas aparentes ou inadequadas, falta de proteção nas luminárias, inexistência de colaboradores específicos para higienização, portas sem vedação, ausência de produtos destinados a higiene nas instalações sanitárias, ausência de sabonetes antissépticos nos lavatórios da área de produção.

Resultado semelhante foi observado por Almeida et al. (2018), em estudo transversal realizado no município de Belo Horizonte, no qual constataram deficiências na localização dos banheiros, inclusive ao seu acesso, ausência de suporte para sabonete líquido, desabastecimento de papel toalha, ausência de lixeira com mecanismo de acionamento por pedal, além do uso de adornos pelos manipuladores.

Esses são fatores que podem gerar alto índice de contaminação cruzada, pois estão envolvidas diretamente com a área produtiva e suas inadequações dificultam o processo de higienização, possibilitando à formação de biofilmes, potencializando os riscos à saúde humana (LONDERO et al., 2019).

Ainda no item de edificações e instalações foi observado que em todos os estabelecimentos não havia um local apropriado para armazenagem dos produtos de limpeza, alguns até sobre as mesas de produção (Figura1), inclusive inseticida. Em trabalho semelhante, Vidal-Martins et al. (2014) observaram que apenas 56\% dos estabelecimentos inspecionados no município de São José do Rio Preto- SP, os produtos químicos eram armazenados de acordo com o estabelecido pela legislação.

O que de fato, é preocupante, pois há um grande risco de contaminação microbiana pela suspensão de partículas e pela formação de aerossóis dos produtos químicos (TANCREDI, SILVA; MARIN, 2006). 
Figura 1- Registros das não conformidades.
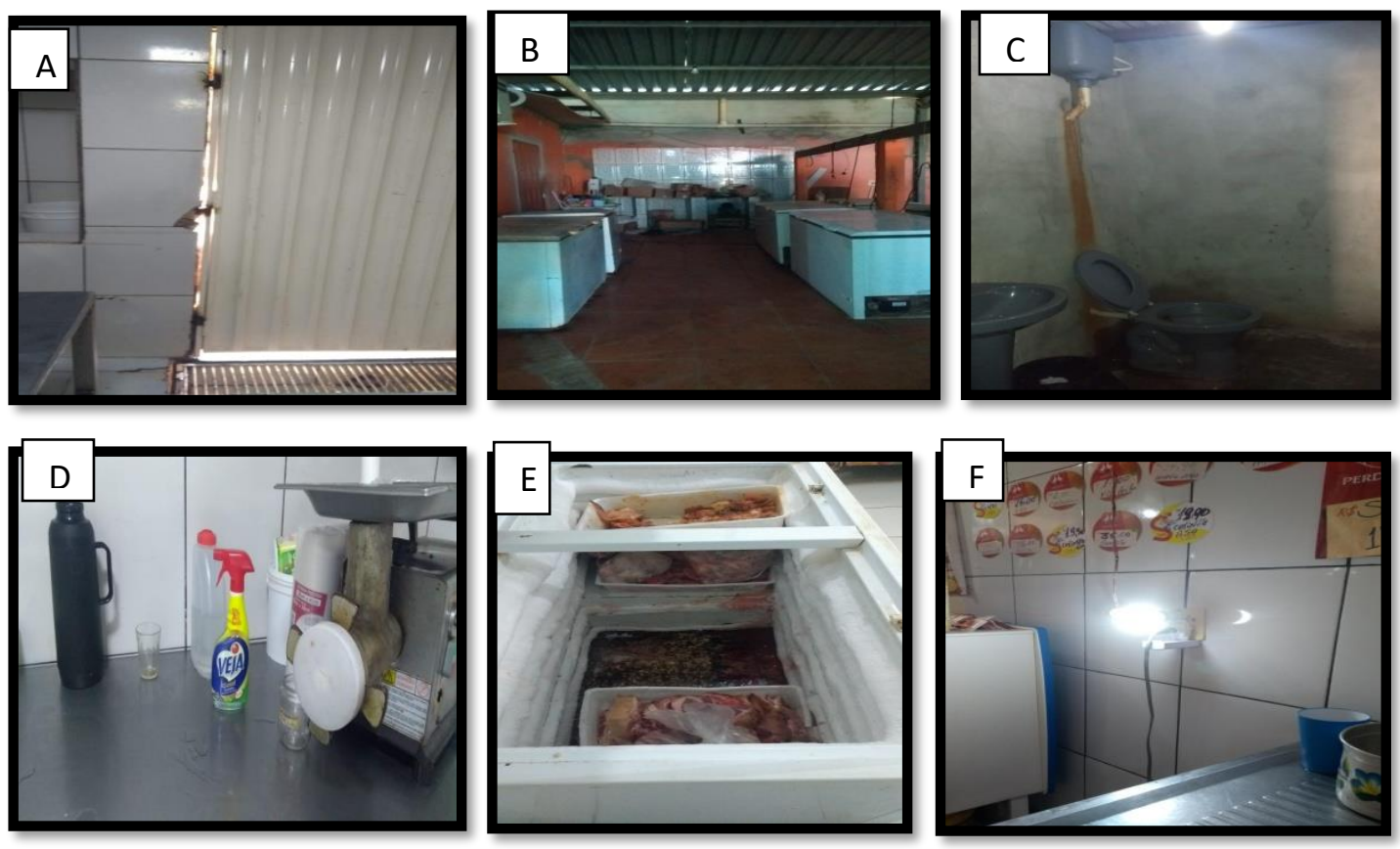

A-Ausência de vedação nas frestas da porta contribuindo ou facilitando a entrada de insetos para o interior do estabelecimento; B- Área de armazenagem com objetos em desuso favorecendo o Acúmulo de poeira, insetos e até roedores; C- Acabamento do banheiro inadequado, ausência de produtos de higiene; D- Materiais de limpeza e objetos estranhos a área de produção; E- Oxidação no fundo do refrigerador; F- Luminária sem proteção com fiação exposta.

Fonte: Autores.

Vale ressaltar que o uso inadequado de inseticidas pode causar intoxicações depois de ingeridos, inalados ou absorvidos pela pele. As intoxicações podem ocorrer por contato direto no preparo, aplicação ou qualquer tipo de manuseio com o produto e por contato indireto, através da água contaminada, utensílios e alimentos (MINISTÉRIO DA SAÚDE, 2015). De acordo com Cantarutti (2005), a população exposta pela ingestão de alimentos contaminados com resíduos de pesticidas está sujeita ao risco tóxico crônico.

Em relação aos equipamentos e utensílios, foram observadas as seguintes não conformidades: inexistência de comprovação de manutenção preventiva e calibração dos maquinários, armazenamento inadequado e desorganizado dos utensílios, equipamentos com oxidação e inadequado estado de conservação, o que maximiza os riscos de contaminação do alimento pronto para a comercialização, contrapondo assim as normas que dispõem a regulamentação técnica de Boas Práticas de Fabricação da RDC nº 216 (2004), conforme apresentados na Tabela 1.

Conforme dados apresentados na Tabela 1, o índice de Não Conformidades em alguns estabelecimentos, foi superior aos itens conformes, demonstrando a deficiência e instabilidade na qualidade dos produtos cárneos oferecidos nos açougues. Isso também ficou claro durante a verificação, em que alguns colaboradores e proprietários revelaram desconhecimento da 
existência de Boas Práticas de Fabricação, que não receberam nenhum tipo de treinamento ou apoio dos órgãos públicos.

Tabela 1- Avaliação quantitativa, conformidades, inconformidades e itens não aplicáveis dos Açougues de Confresa-MT.

\begin{tabular}{|c|c|c|c|c|c|c|c|c|c|c|c|c|}
\hline \multirow[t]{2}{*}{$\begin{array}{l}\text { Estabelecimentos/Itens } \\
\text { avaliados }\end{array}$} & \multicolumn{3}{|c|}{$\begin{array}{l}\text { Edificações } \\
\text { e instalações }\end{array}$} & \multicolumn{3}{|c|}{$\begin{array}{l}\text { Equipamentos } \\
\text { e utensílios }\end{array}$} & \multicolumn{3}{|c|}{$\begin{array}{l}\text { Vestuário } \\
\text { e hábitos } \\
\text { de Higiene }\end{array}$} & \multicolumn{3}{|c|}{$\begin{array}{l}\text { Produção } \\
\text { e transporte } \\
\text { do alimento }\end{array}$} \\
\hline & $\mathbf{C}$ & NC & $\mathbf{N A}$ & $\mathbf{C}$ & NC & $\mathbf{N A}$ & $\mathbf{C}$ & $\mathrm{NC}$ & $\mathbf{N A}$ & $\mathbf{C}$ & $\mathbf{N C}$ & NA \\
\hline Açougue A & 23 & 27 & 14 & 9 & 7 & 0 & 6 & 5 & 0 & 2 & 5 & 0 \\
\hline Açougue B & 19 & 26 & 20 & 8 & 6 & 1 & 3 & 7 & 1 & 2 & 7 & 0 \\
\hline Açougue $\mathbf{C}$ & 26 & 21 & 18 & 12 & 3 & 1 & 7 & 4 & 0 & 2 & 4 & 0 \\
\hline Açougue D & 34 & 15 & 14 & 11 & 0 & 0 & 7 & 3 & 3 & 2 & 3 & 0 \\
\hline Açougue $\mathrm{E}$ & 18 & 20 & 26 & 5 & 7 & 2 & 2 & 8 & 0 & 2 & 8 & 0 \\
\hline Açougue $F$ & 25 & 22 & 19 & 5 & 4 & 1 & 3 & 6 & 2 & 2 & 6 & 0 \\
\hline
\end{tabular}

Fonte: Autores.

Os dados expostos na Tabela 1 expressam a precariedade em relação aos hábitos de higiene, onde foi observado que não há uma lavagem cuidadosa e frequente das mãos antes ou após a manipulação da carne, além da ausência de cartazes de orientação sobre a correta de lavagem das mãos. Resultado semelhante foi observado por Stoffel e Piemolini-barreto (2018), em que verificaram índice de 53,33\% de inconformidades quanto ao procedimento de higienização das mãos, em restaurante da culinária da Serra Gaúcha-RS.

No que se refere ao programa de controle de saúde $90 \%$ dos estabelecimentos desconhecem a obrigatoriedade de supervisão periódica do estado de saúde dos manipuladores, além da inexistência de programa de capacitação relacionado à higiene pessoal e a manipulação dos alimentos. Situação também verificada por Filho, Castro e Calvet (2018), em boxes de comercialização de pescado no município de Timon- MA, no qual constatou que $100 \%$ dos indivíduos participantes de sua pesquisa, tanto funcionários quanto proprietários, não receberam qualquer capacitação de higienização ou de Boas Práticas de Manipulação para o exercício de suas funções.

O uso adequado de EPIs além de contribuir para a segurança dos manipuladores evita ou minimiza os riscos de contaminações cruzadas, já que o uso da touca impede a queda de cabelos sobre os alimentos, as luvas impedem o contato direto das mãos com alimento reduzindo o risco de proliferação de microrganismos caso não haja uma higienização frequente 
ou adequada das mãos. Já o uso de uniformes e aventais evita o contato direto do manipulador com o alimento, uma vez que os manipuladores passam por diferentes ambientes no local de trabalho, principalmente se este utiliza suas roupas civis.

Foi observada ausência e/ou deficiência no uso de EPI’s, como falta de luvas, toucas, aventais, máscara, calça na cor clara (já que esta é composta pela roupa civil do manipulador). Isso contrapõe as orientações da Anvisa (BASIL, 2004) a qual instrui a troca de uniformes devem ocorrer diariamente e usados exclusivamente nas dependências internas do estabelecimento já as roupas e os objetos pessoais devem ser guardados em local específico e reservados para esse fim. Resultado semelhante foi observado também por Guimarães\& Nascimento (2018), estes verificaram que 62\% dos manipuladores não faziam uso de qualquer EPI's em duas feiras livres de Belém-PA.

Conforme observado na Figura 1, imagem D, não há condições estruturais, nem materiais de higiene, inexistência de quadros de orientações sobre a correta higienização das mãos, contrapondo as orientações da Anvisa (BRASIL, 2004) em que incentiva os manipuladores a realizarem a lavagem cuidadosa das mãos, antes e após manipular alimentos, após interrupção do serviço, após tocar materiais contaminados, depois do uso de sanitários, além disso, o estabelecimento deve ter afixados cartazes de orientação aos manipuladores sobre a correta lavagem e antissepsia das mãos e demais hábitos de higiene, em locais de fácil visualização, inclusive nas instalações sanitárias e lavatórios.

No estabelecimento A, C e E, foi observado presença de insetos (moscas e barata), inclusive no estabelecimento. E havia um gato embaixo do lavatório da área de produção. Mascarenhas et al. (2020), também verificou presença de moscas e baratas somadas a animais domésticos como cães e gatos, em estudo higiênico-sanitário dos boxes comercializadores de carnes no estado de Alagoas.

Oportunamente bactérias podem ser transmitidas como Escherichia coli, Klebsiellasp, Enterobactersp, Pseudomonassp, Staphylococcus aureus, Streptococcus sp, Enterococcus s., já as moscas são vetores de bactérias como Vibriocholerae e Shigellasp, vírus entéricos, protozoários como Giardia lamblia e Cryptosporidiumparvum, helmintos como Ascaris sp., Trichuris sp., oxiurídeos e Taeniasolium (ALVES, 2009).

Nos estabelecimentos A e E (foi possível observar esse item devido ao horário de verificação do checklist, logo na abertura e outro próximo ao horário de fechamento), foi observado que para realizar o descogelamento das carnes e frangos congelados é feita uma submersão desses produtos em uma bacia com água, chegando a pernoitar de um dia para outro. Confrontando as orientações da Anvisa (BRASIL, 2015), que recomenda que o 
descongelamento deve ser efetuado em condições de refrigeração à temperatura inferior a $5^{\circ} \mathrm{C}$ (cinco graus Celsius), e devendo ser mantidos sob refrigeração se não forem imediatamente utilizados, não podendo ser recongelados.

Quanto à produção e transporte do alimento foram observados, que de forma unânime nenhum dos estabelecimentos tem um local protegido e isolado para a recepção de matériaprima e embalagens. Quando a legislação orienta que a recepção das matérias-primas, dos ingredientes e das embalagens deve ser realizada em área protegida e limpa adotando-se medidas que evitem que esses insumos contaminem o alimento preparado (BRASIL, 2004), evitando que haja contaminação cruzada ocasionada pelo ambiente.

\section{Considerações}

É notória as condições precárias de higiene dos estabelecimentos onde são manipulados os alimentos; falta de adequações estruturais; falta de organização; falta de higiene pessoal dos colaboradores e dos proprietários. Para adequar-se as normas vigentes, é necessário informar, ensinar, implementar e incentivar as Boas Práticas de Fabricação durante os processos de manipulação, distribuição e comercialização dos alimentos, além da conscientização e capacitação adequada dos manipuladores de alimentos, que são os principais responsáveis pela contaminação. E ainda, é importante que os órgãos responsáveis invistam em fiscalização, em campanhas para conscientização da população sobre os riscos que um alimento contaminado pode trazer a saúde humana ao ser ingerido.

\section{Referências Bibliográficas}

ALMEIDA, A. A. P. et al.. Desenvolvimento de manual de boas práticas para capacitação de manipuladores se um banco de alimentos na cidade de Belo Horizonte, MG. Revista Higiene Alimentar, v. 32 n 278/279, p 41-45, 2018.

ALVES, C. de E. F.M.. Bactérias enteropatogênicas envolvidas em doenças transmitidas por alimento e diarréias agudas em minas gerais no período de 2006 a 2008. Monografia apresentada ao Programa de Pós Graduação em Microbiologia Aplicada às Ciências da Saúde do Instituto de Ciências Biológicas da UFMG, como requisito parcial para a obtenção do grau de Especialista em Microbiologia. Belo Horizonte, 2009.

BRASIL. Agência Nacional de Vigilância Sanitária. RDC no 216 de 13 de setembro de2004. Dispõe sobre Regulamento Técnico de Boas Práticas para serviços de alimentação.

BRASIL. Agência Nacional de Vigilância Sanitária. RDC no 275, de 21 de outubro de 2002. Dispõe sobre o Regulamento Técnico de Procedimentos Operacionais Padronizados aplicados aos Estabelecimentos Produtores/Industrializadores de Alimentos e a Lista de Verificação das Boas Práricas de Fabricação em Estabelecimentos Produtores/ Industrializadores de Alimentos. 
BRASIL, Agência Nacional de Vigilância Sanitária. Resolução da Diretoria Colegiada no 43, de $1^{\circ}$ de Setembro de 2015. Dispõe sobre a prestação de serviços de alimentação em eventos de massa.

CANTARUTTI, T. F. P..Risco tóxico de resíduos de pesticidas em alimentos e toxicidade reprodutiva em ratos wistar. Dissertação apresentada como requisito parcial à obtenção do grau de Mestre, pelo Curso de Pós-Graduação em Farmacologia, do Setor de Ciências Biológicas da Universidade Federal do Paraná. Curitiba, 2005.

FILHO, L. S. F.; CASTRO, S. S. V; CALVET, R. M.Aspectos higienicossanitários dos boxes de comercialização de pescado no mercado municipal José E mídio em Timon, MA. Revista Higiene alimentar, v. 32, $\mathrm{n}^{\circ}$ 278/279, p.63-67, mar-abr, 2018.

GUIMARÃES, I. R. B.; NASCIMENTO, F. das C.A. do. A prática na manipulação de alimentos em duas feiras livres de Belém, PA. Revista Higiene alimentar, v. 32, nº 276/277, p.48-52, jan-fev, 2018.

IBGE- Instituto Brasileiro de Geografia e Estatística. Confresa. 2017 IBGE - Instituto Brasileiro de Geografia e Estatística |v4.4.19. Disponível em:

https://cidades.ibge.gov.br/brasil/mt/confresa/panorama. Acesso em: 26 de Janeiro de 2021.

LONDERO, A. et al.

CharacterizationandsubtypingofListeriamonocytogenesstrainsfrombutcher shops

LWT - Food Science and Technology, v.113, p.1-6, 2019.

MASCARENHAS, A. F. de G. t al.. Condições estruturais e higiênico-sanitárias dos boxes comercializadores de carnes em um mercado público de Alagoas. Braziliam Journal of Development, Curitiba, v. 6, n.12, p.95439-95454 dec. 2020. ISSN 2525-8761

MINISTÉRIO DA SAÚDE. Biblioteca virtual em saúde - Intoxicação por agrotóxicos. Setembro de 2015- Ministério da Saúde () 2021 - Todos Direitos Reservados - V 1.3. Disponível em: https://bvsms.saude.gov.br/dicas-em-saude/2084-intoxicacao-por-agrotoxicos. Acesso em: 05 de março de 2021.

SILVA JUNIOR, E. A..Manual de Controle Higiênico-Sanitário em Serviços de Alimentação. São Paulo: Livraria Varela, 2010.

STOFFEL, F.; PIEMOLINI-BARRETO, L. T.. Avaliação de Boas Práticas em restaurante especializado em culinária oriental. Revista Higiene alimentar, v. 32, nº 276/277, p.53-57, jan-fev, 2018.

TANCREDI, R. C. P.; SILVA, Yoni.; MARIN, V. A. Regulamentos Técnicos sobre Condições Higiênico-Sanitárias. Manual de Boas Práticas e POPs para Indústria/ Serviços de Alimentação. Rio de Janeiro: L.F. Livros de Veterinária LTDA, 2006.

VIDAL-MARTIS, A. M. C. et al.. Implantação e avaliação do programa de boas práticas de manipulação em açougues do Município de São José do Rio Preto. Revista Brasileira de Higiene e Sanidade Animal, v. 08, n. 2, p. 73-86, abr-jun, 2014. ISSN 1981-2965. 